\title{
Computational and Experimental Study on Pressure Drop in a Fluidised Bed with Different Air Distributor Designs
}

\author{
A.S.M. Yudin ${ }^{*}$, A.N. Oumer, N.M.F. Roslan and M.A. Zulkarnain \\ Department of Mechanical, College of Engineering, Universiti Malaysia Pahang, Lebuhraya Tun Razak, 26300 Kuantan Pahang, Malaysia \\ Phone: +6094246378; Fax: +609424622
}

\begin{abstract}
Fluidised bed combustion (FBC) has been recognised as a suitable technology for converting a wide variety of fuels into energy. In a fluidised bed, the air is passed through a bed of granular solids resting on a distributor plate. Distributor plate plays an essential role as it determines the gas-solid movement and mixing pattern in a fluidised bed. It is believed that the effect of distributor configurations such as variation of free area ratio and air inclination angle through the distributor will affect the operational pressure drop of the fluidised bed. This paper presents an investigation on pressure drop in fluidised bed without the presence of inert materials using different air distributor designs; conventional perforated plate, multi-nozzles, and two newly proposed slotted distributors $\left(45^{\circ}\right.$ and $90^{\circ}$ inclined slotted distributors). A 3-dimensional Computational Fluid Dynamics (CFD) model is developed and compared with the experimental results. The flow model is based on the incompressible isothermal RNG k-epsilon turbulent model. In the present study, systematic grid-refinement is conducted to make sure that the simulation results are independent of the computational grid size. The non-dimensional wall distance, $y^{+}$is examined as a key factor to verify the grid independence by comparing results obtained at different grid resolutions. The multi-nozzles distributor yields higher distributor pressure drop with the averaged maximum value of $749 \mathrm{~Pa}$ followed by perforated, $45^{\circ}$ and $90^{\circ}$ inclined distributors where the maximum pressure drop recorded to be about one-fourth of the value of the multi-nozzles pressure drop. The maximum pressure drop was associated with the higher kinetic head of the inlet air due to the restricted and minimum number of distributor openings and low free area ratio. The results suggested that low-pressure drop operation in a fluidised bed can be achieved with the increase of open area ratio of the distributor.
\end{abstract}

ARTICLE HISTORY

Revised: $20^{\text {th }}$ April 2020

Accepted: $29^{\text {th }}$ June 2020

\section{KEYWORDS}

Computational fluid dynamics (CFD);

Air distributor;

Flow dynamics;

Swirling fluidised bed;

Slotted distributor

\section{INTRODUCTION}

One of the key parameters affecting the successful operation of fluidised beds is the distributor plate. It is known that the efficient and stable operation of a fluidised bed is sensitively controlled by the design of the distributor [1, 2]. The hydrodynamics of flow in the dense phase, quality of gas dispersion, bubble size and its behaviour, gas-solids contacting, gas hold-up, residence time distribution of gas, solid movement and mixing pattern are some of the aspects that are affected by the distributor design [3, 4]. Practically, distributors for fluidised bed have taken a variety of designs. The designs are classified into two physical forms; static and rotating distributors. The distributors are later grouped based on the direction of air entering into the distributor, viz., normal direction, lateral direction and inclined direction.

Perforated plate distributor consists of holes arranged in either square or triangular pitches that are distributed over the distributor's area. The percentage opening area; or some might refer to it as - perforated ratio is calculated by dividing the total number of holes area over the distributor area. The work of Dong et al. [5] investigated the importance of perforated ratios on the distributor and bed pressure drop, solid hold-up, and gas-solid behaviour. Three different types of perforated distributors having $0.46 \%, 0.86 \%$ and $1.10 \%$ perforated ratios were investigated by utilising the CFD simulation and comparison with experimental and available published data. The results showed that as superficial velocity progressed, the distributor pressure drop increased with decreasing perforated ratio due to the increase of airflow resistance. However, solid circulation and gas-solid distribution were recorded homogenous in the bed of $0.46 \%$ perforated ratio than that of $0.86 \%$ and $1.10 \%$. The authors concluded that fluidisation was more stable in the bed operated in low perforated ratio distributor due to adequate pressure drop across the distributor to provide uniform gas distribution.

CFD simulation on the hydrodynamics of the bubbling fluidised bed gasifier with a nozzle-type gas distributor was studied by Ngo et al. [6]. Two cases (one for ideal and the other for actual) of air distribution with the nozzle-type distributor were considered in their 3D CFD simulations. Modelling the fluidised bed with ideal air entering the system showed significant deviation from the real phenomenon as observed in the real case system. Thus, the real case of distributor geometry should be considered in modelling the air distribution in fluidised bed system. Attempts to improve mixing through distributor designs have been comprehensively investigated by implementation of rotating distributor plate [7-9]. Radial dispersion of particles resulted from the rotation motion of the mechanically rotated distributor on the 
vertical axis was reported capable of improving radial and axial mixing inside the bed [7, 10]. Furthermore, elimination of the aggregates and defluidised region at location just above the distributor can be achieved by using rotating distributor [9].

Alternatively, the radial and axial motion as per rotated distributor is made possible by swirling-type distributor [1116]. The distributor is neither rotates nor spins. The inclined entrainment of gas through the distributor produces two velocity components: the vertical component causes fluidisation and the tangential component that responsible for swirling motion in bed [14]. It is thus anticipated that swirling-type distributor might improve particulate mixing through swirling motion of bed materials without implementation of electric motor or mechanically assisted devices, as mentioned previously. However, the current swirling distributor designs used overlapping blades that limits the application of fluidisation only to larger bed size materials.

Considering most of the fluidisation processes were operated with conventional distributor, the present paper emphasises the study of pressure drop by using newly proposed slotted distributors that consists of few slotted areas with different inclination angles. The flow dynamics of conventional distributors: perforated plate, multi-nozzles, and newly proposed slotted distributors $\left(45^{\circ}\right.$ and $90^{\circ}$ slotted distributors) in a fluidised bed are simulated through CFD, and their pressure drop is compared and validated with the experimental results.

\section{NUMERICAL MODEL DESCRIPTION}

Four different designs of air distributors with $D=115 \mathrm{~mm}$ diameter and $\Delta z=8 \mathrm{~mm}$ thickness were modeled in the simulations. The first distributor was perforated distributor plate consisting of $N=89$ holes (each $d_{o}=4 \mathrm{~mm}$ diameter) arranged in evenly spaced concentric axes [17]. This distributor was considered as a reference distributor for conventional fluidise bed. The multi-nozzles distributor was fabricated from 8 pieces of $3 / 4$ " steel bolts screwed on the aluminum plate. At the bottom of each bolt, a $d_{o}=4 \mathrm{~mm}$ diameter hole was drilled and branches radially to two holes at the top giving " $\mathrm{T}$ " shaped air passages. The ratio of the opening area is $\beta=2 \%$. The circular edged distributor (see Figure 1(c)) from the previous work of Shukrie et al. [18] was used in the simulation and experiment. The distributor consists of 8 air slots with $6.5 \mathrm{~mm}$ diameter and $29 \mathrm{~mm}$ long circular edged openings extended to the peripheral of the distributor. The air angle of attack was perpendicular to the plate $\left(90^{\circ}\right)$. The distributor geometry was further modified to introduce a novel swirling distributor by making the circular edge openings with $45^{\circ}$ inclined air intakes (see Figure 1d). The opening ratio for both of the distributors is $\beta=13 \%$. The geometric parameters and the photographs of the distributors are presented in Table 1 and in Figure 1 respectively.

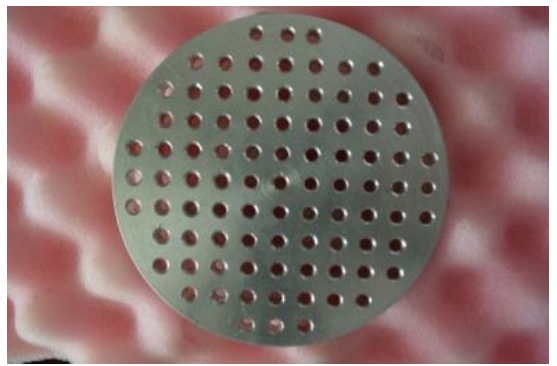

(a)

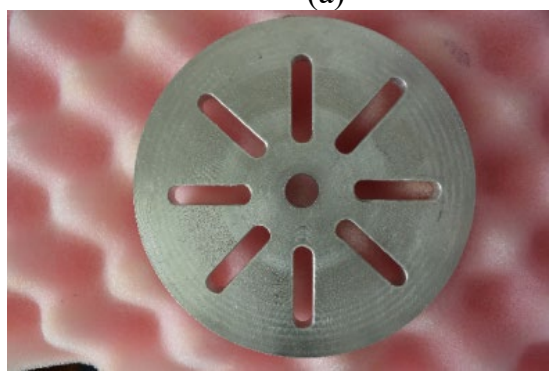

(c)

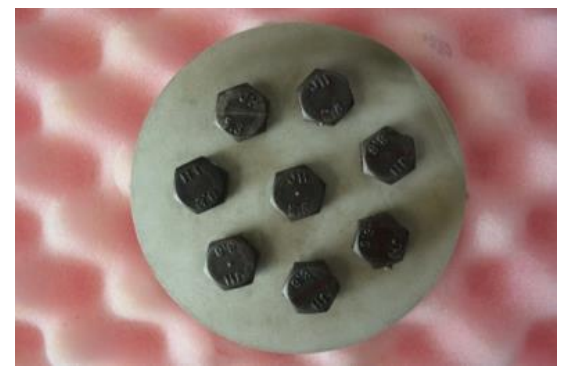

(b)

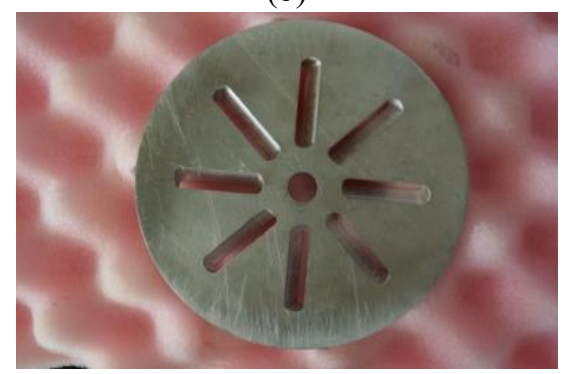

(d)

Figure 1. Photographs of the distributor (a) perforated plate, (b) multi-nozzles, (c) $90^{\circ}$ circular edged distributor and (d) $45^{\circ}$ inclined distributor.

Table 1. Distributor geometric parameters.

\begin{tabular}{lccccc}
\hline Distributor & $D(\mathrm{~m})$ & $\Delta z(\mathrm{~m})$ & $d_{o}(\mathrm{~m})$ & $\beta[\%]$ & $N[-]$ \\
\hline Perforated plate & 0.115 & 0.008 & 4 & 11 & 89 \\
$90^{\circ}$ & 0.115 & 0.008 & - & 13 & 9 \\
$45^{\circ}$ & 0.115 & 0.008 & - & 13 & 9 \\
Multi-nozzles & 0.115 & 0.008 & 4 & 2 & 16 \\
\hline
\end{tabular}


The airflow in the fluidised beds without the presence of the bed particles was simulated in a three-dimensional domain that made of two vertical cylinders connected by different types of distributors. The schematic of the computational domains with different distributors is shown in Figure 2. Four different distributors namely perforated, multi-nozzles, $90^{\circ}$ and $45^{\circ}$ distributors, were considered in the simulation. All components: air plenum chamber, distributors and bed were incorporated into the simulation with full-scale so that actual sizes and geometries were considered.

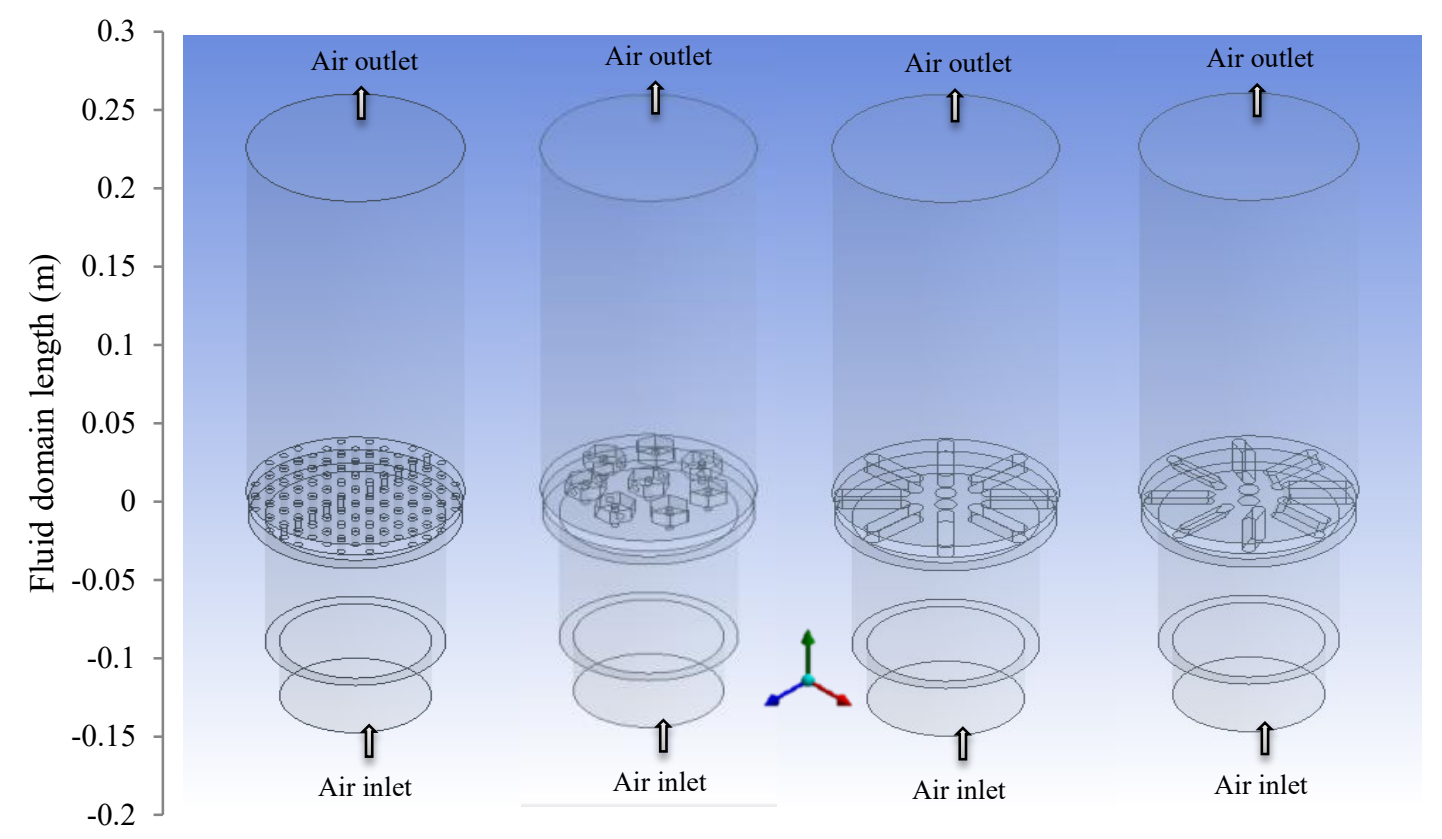

Figure. 2. Schematics of the computational domain. From left to right: perforated, multi-nozzles, $90^{\circ}$ and $45^{\circ}$ distributors.

The mathematical formulation was based on the assumptions that the flow field is incompressible, turbulent, isothermal, and steady flow. Therefore, the continuity and momentum governing equations were solved along with the transport equations of the turbulent kinetic energy and its dissipation rate. The continuity and momentum equations have the form of:

$$
\begin{gathered}
\nabla \cdot(\boldsymbol{V})=0 \\
\rho \nabla \cdot(\boldsymbol{V} \boldsymbol{V})=-\nabla p+\nabla \cdot \boldsymbol{\tau}+\rho g
\end{gathered}
$$

where, $\boldsymbol{V}$ is the velocity vector, $\rho$ is the density, $p$ is the hydrostatic pressure, and $g$ is the gravitational acceleration. The term $\dot{\gamma}$ represents the shear rate, and $\tau$ is the total stress tensor.

The Re-Normalization Group ( $\mathrm{RNG}$ ) $\mathrm{k}-\varepsilon$ model was used in this study due to the fact that it is widely used turbulence model for the solution of practical engineering flow problems [19-23]. Such model is a semi-empirical model built on model transport equations for the turbulence kinetic energy $k$ and its dissipation rate $\varepsilon$. The transport equation for the RNG $k-\varepsilon$ model can be expressed as:

$$
\begin{gathered}
\rho \frac{\partial}{\partial x_{i}}\left(k V_{i}\right)=\frac{\partial}{\partial x_{j}}\left[\left(\mu+\frac{\mu_{t}}{\sigma_{k}}\right) \frac{\partial k}{\partial x_{j}}\right]+G_{k}+G_{b}-\rho \varepsilon-Y_{M} \\
\rho \frac{\partial}{\partial x_{i}}\left(\varepsilon V_{i}\right)=\frac{\partial}{\partial x_{j}}\left[\left(\mu+\frac{\mu_{t}}{\sigma_{\varepsilon}}\right) \frac{\partial \varepsilon}{\partial x_{j}}\right]+C_{1 \varepsilon} \frac{\varepsilon}{k}\left(G_{k}+C_{3 \varepsilon} G_{b}\right)-C_{2 \varepsilon} \rho \frac{\varepsilon^{2}}{k}+R_{\varepsilon}
\end{gathered}
$$

where $k, \varepsilon, \mu, \mu_{t}$ are turbulence kinetic energy, rate of dissipation, dynamic viscosity of air, and turbulent (eddy) viscosity respectively. The terms $\sigma_{k}, \sigma_{\varepsilon}, G_{k}, G_{b}, Y_{M}$ represent the turbulent Prandtl numbers for $k$, turbulent Prandtl numbers for $\varepsilon$, generation of turbulence kinetic energy due to the mean velocity gradients, generation of turbulence kinetic energy due to buoyancy, and contribution of the fluctuating dilatation in compressible turbulence to the overall dissipation rate respectively. The other parameters $C_{1 \varepsilon}, C_{2 \varepsilon}, C_{3 \varepsilon}$ are constants. The turbulent viscosity was calculated using Eq. (5).

$$
\mu_{t}=\rho C_{\mu} \frac{k^{2}}{\varepsilon}
$$


Other model constants are equal to $C_{1 \varepsilon}=1.42, C_{2 \varepsilon}=1.68$ and $C_{3 \varepsilon}=0.0845$. Despite of its robustness, the RNG $k-\varepsilon$ turbulence model has additional term $R_{\varepsilon}$ in its equation that makes the model more responsive to the rapid strain and streamline curvature - improves the accuracy compare to the standard $k-\varepsilon$ model [24].

The working fluid domain in the model was air at room temperature and it entered into the plenum chamber with known specific pressure. The inlet static pressure was measured experimentally and being used as the boundary inputs for the simulation. The initial gauge pressure at the outlet boundary was assumed to be $100 \mathrm{~Pa}$ for initialisation purpose, while the reference pressure was adjusted accordingly. The non-slip boundary condition was applied on the remaining solid boundaries. The boundary conditions applied for the simulation with different distributor design are tabulated in Table 2. At inlet and outlet, the turbulence was specified using the intensity and length scale specifications. Both intensity and length ratio parameters were calculated from the readily known values extracted from the experimental data. Thus, the turbulence intensity $(I)$ and the turbulent length ratio $(L)$ for internal flows inside a duct can be obtained using Eqs. (6) and (7) [25].

$$
\begin{gathered}
I=0.16 / R e^{\frac{1}{8}} \\
L=0.07 l
\end{gathered}
$$

Table 2. Flow parameters and inlet boundary conditions for different distributor designs of fluidised bed.

\begin{tabular}{cccccc}
\hline \multirow{2}{*}{ Distributor } & $\begin{array}{c}\text { Blower frequency } \\
(\mathrm{Hz})\end{array}$ & $\begin{array}{c}U_{\text {inlet }} \\
(\mathrm{m} / \mathrm{s})\end{array}$ & Re inlet & $I(\%)$ & $P 1(\mathrm{~Pa})$ \\
\hline \multirow{3}{*}{ Perforated plate } & 15 & 0.86 & 4337 & 5.6 & 81.4 \\
& 30 & 2.57 & 12961 & 4.9 & 280.5 \\
& 50 & 4.52 & 22794 & 4.6 & 687.4 \\
\hline \multirow{3}{*}{$90^{\circ}$} & 15 & 0.86 & 4337 & 5.6 & 82.4 \\
& 30 & 2.62 & 13213 & 4.9 & 285.4 \\
\hline \multirow{3}{*}{$45^{\circ}$} & 50 & 4.56 & 22996 & 4.6 & 715.0 \\
& 15 & 0.86 & 4337 & 5.6 & 79.4 \\
& 30 & 2.44 & 12305 & 4.9 & 281.5 \\
Multi-nozzles & 50 & 4.51 & 21635 & 4.6 & 714.9 \\
& 15 & 0.86 & 4337 & 5.6 & 78.5 \\
& 30 & 2.50 & 12608 & 4.9 & 313.8 \\
\hline
\end{tabular}

The tetrahedron computational grids were chosen by implementing patch conforming meshing method with proximity and curvature as advanced size function. Enhanced wall function was employed and special wall treatment was given when using $k-\varepsilon$ turbulent model as it primarily valid in a region somewhat away from the walls. The near-wall model is sensitive to the grid resolution which is assessed in terms of non-dimensional wall resolution, $y^{+}$.

$$
y^{+}=\frac{\rho U_{\tau} \Delta y}{\mu}
$$

where, $U_{\tau}$ is friction velocity and $\Delta y$ is the distance between the wall and the first grid. To obtain sufficiently fine mesh in the wall and distributor section where the flow will experience rapid change in velocity and pressure, sufficiently smooth transition inflation layers were adopted to make sure that the non-dimensional wall resolution $y^{+}$falls under the validated boundary layer region, in this case, $y^{+}<5$ was chosen [26]. The thickness of the first layer, $\Delta y$ and number of inflation layers were varied according to the geometry of fluid domains and are illustrated in Figure 3.

In the present study, systematic grid-refinement was conducted to make sure that the simulation results are independent of the computational grid size. The non-dimensional wall distance, $y^{+}$was examined as key factor to verify the grid independence by comparing results obtained at different grid resolutions. Identical simulations were performed on four grid sizes for all distributor types in order to check for grid independence. Shown in Figure 4 are variations of the non-dimensional wall normal distance $y^{+}$along the distributors' wall length. Thus, the 3D geometries were discretized using 1,776,339, 569,938, 528,789 and 606,714 grid sizes.

The default solver settings were selected because pressure-based solver was used to solve the steady state problem. The governing equations were solved using the finite-volume method (FVM). In these calculations, the second order upwind scheme based on multidimensional linear reconstruction approach was used. The Semi-Implicit Method for Pressure Linked Equations(SIMPLE) algorithm for pressure-velocity coupling with second order upwind discretisation scheme was used to obtain solution for the equations of momentum, turbulence kinetic energy and turbulence dissipation rate, and Reynolds stresses [27]. These computations were carried out using a commercial FVM solver (ANSYS FLUENT'т 14.5). All simulations were carried out on a HP Z400 desktop with an Intel Xeon Quad-Core processor unit 
(3.2 GHz, 12 GB RAM). The convergence criterion used for the simulation was specified that the residual of the equations drops more than three orders of magnitude.

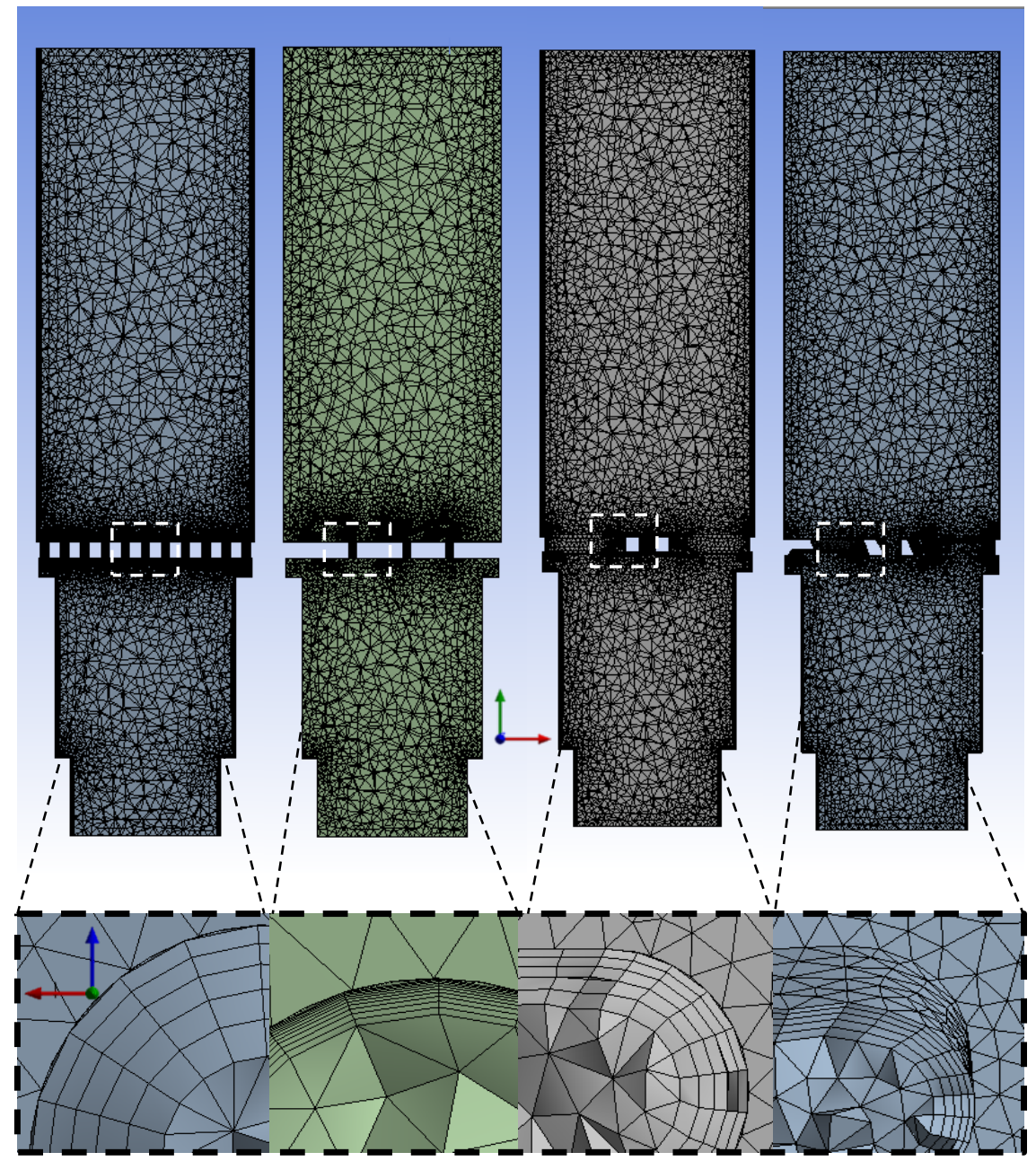

Figure. 3. Meshing structure and enlarged top view of inflation layers in distributor region for: perforated nozzle, $90^{\circ}$ and $45^{\circ}$ distributor (from left to right).

\section{RESULTS AND DISCUSSION}

\section{Comparison of Experiment and CFD}

The experimental and simulated distributor pressure drops were compared to verify the accuracy of the simulation results. The blower that supplied fluidised air to the fluidised bed is operated with maximum speed at $50 \mathrm{~Hz}$. Inlet air velocity corresponding to 10,30 and $50 \mathrm{~Hz}$ blower frequencies were considered in the simulations (low, medium and high speed). The pressure drops across the distributors, pressure below the distributor (through pressure tap point P1), the velocity at the entry to the plenum chamber and outlet of the bed were obtained experimentally. Then the static pressure at the inlet to the distributor (P1) was used as the boundary inputs for the CFD simulation. The simulated distributor pressure drops were obtained by taking the pressure differences along the fluid domain lengths at locations $-0.05 \mathrm{~m}(\mathrm{P} 1)$ below the distributor and $0.01 \mathrm{~m}(\mathrm{P} 2)$ just above the distributor, respectively.

The simulated pressures over the vertical length of the bed for different distributor designs are plotted in Figure 5. The pressure seemed to surge and plunge by a fairly amount at locations before and after the distributor. The pressure right after the distributor were observed to be unstable but recovered at the exit of the fluidised bed domain. For all three velocities, a major drop in pressure was observed by the multi-nozzles distributor due to the low free area ratio at $2 \%$. 


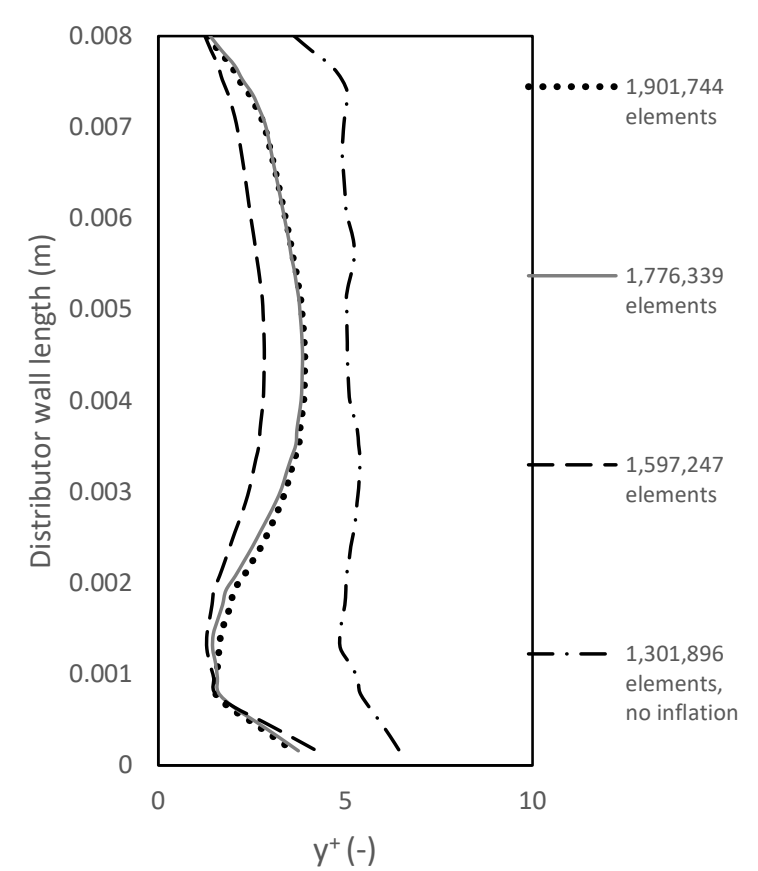

(a)

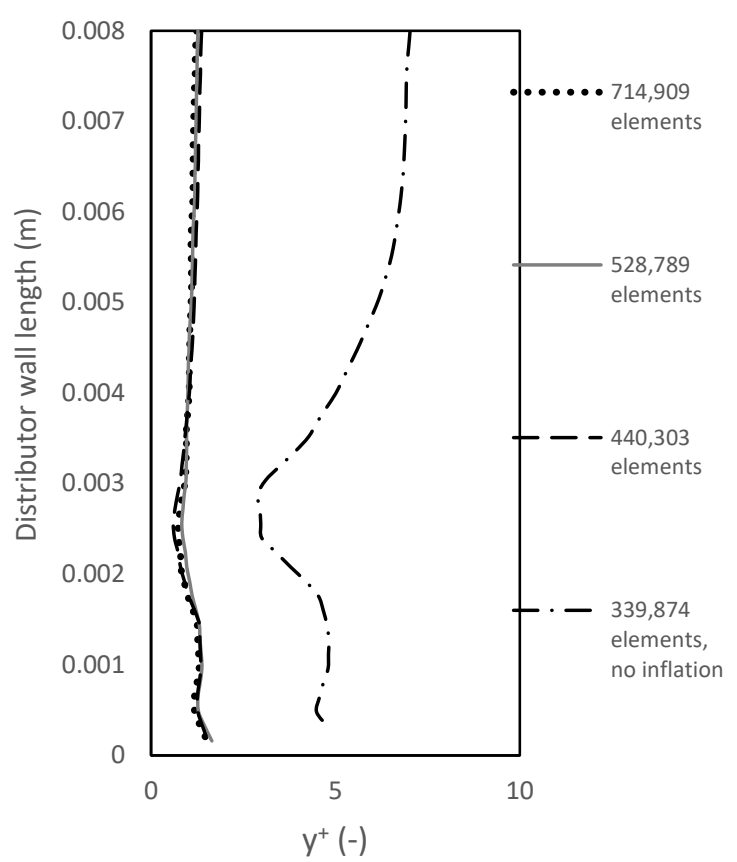

(c)

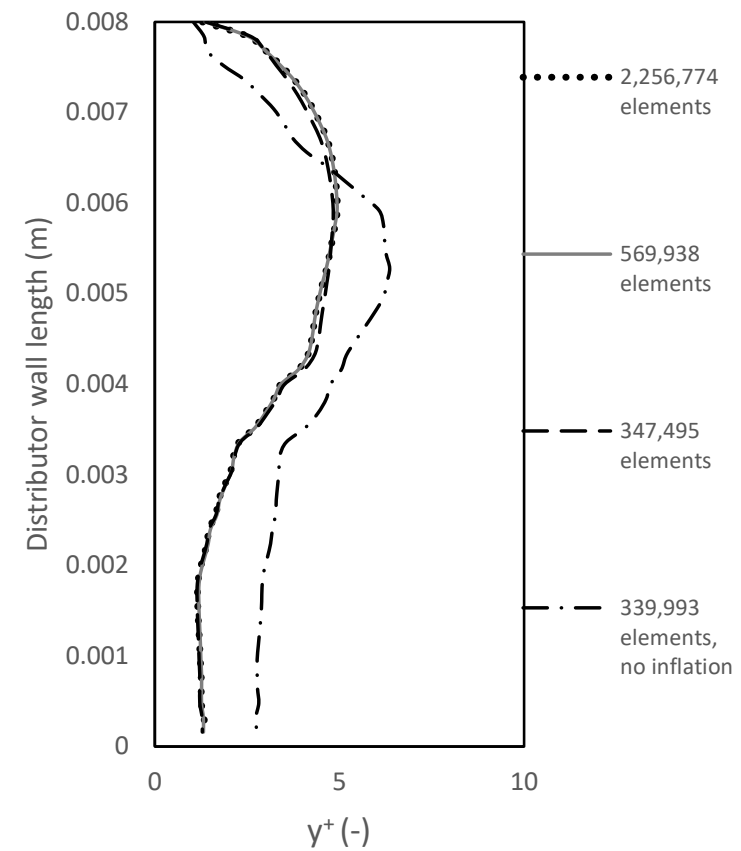

(b)

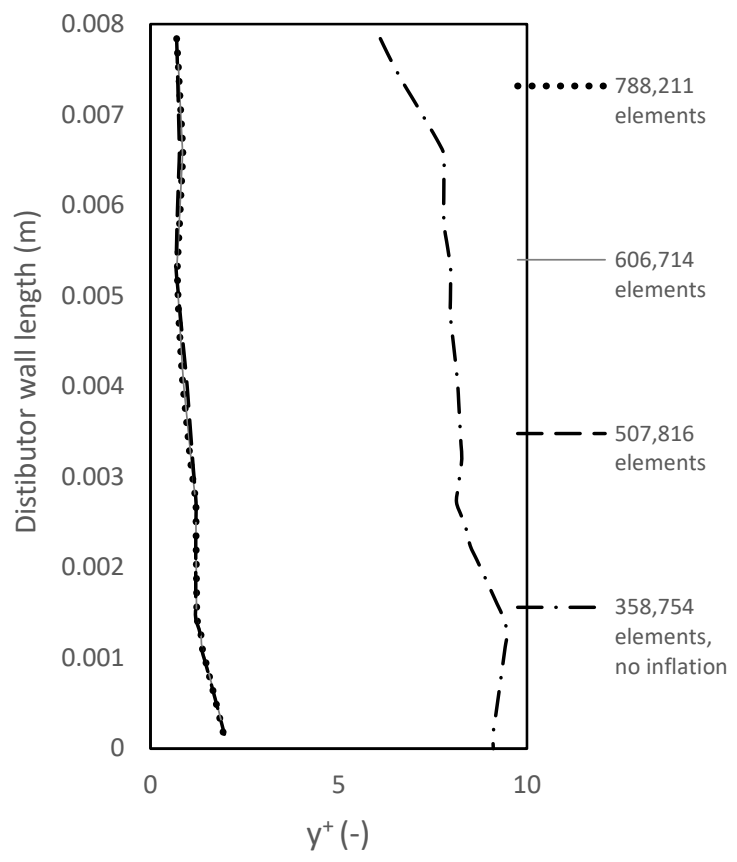

(d)

Figure 4. Variations the non-dimensional wall normal distance $\boldsymbol{y}^{+}$along the distributors' wall length for (a) perforated, (b) nozzle, (c) $90^{\circ}$ and (d) $45^{\circ}$.

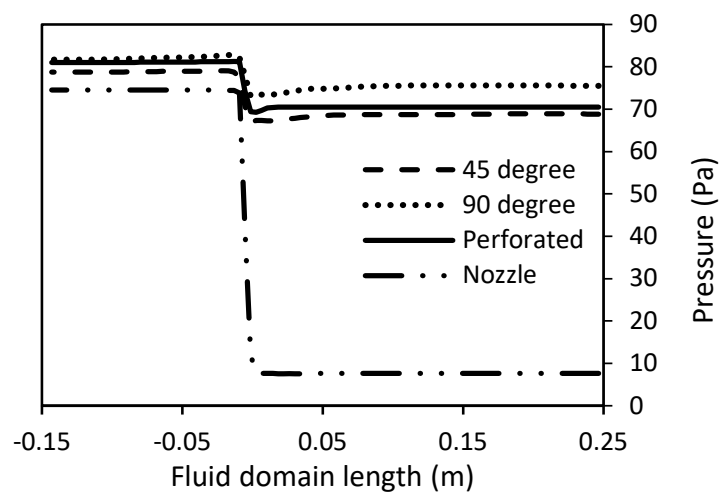

(a)

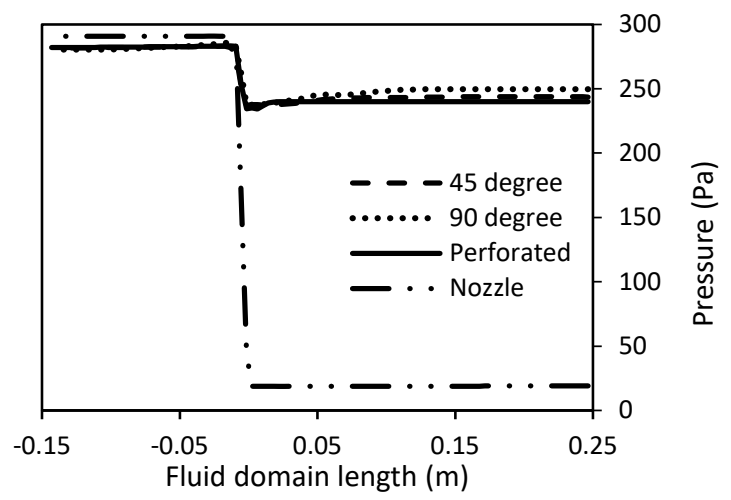

(b) 


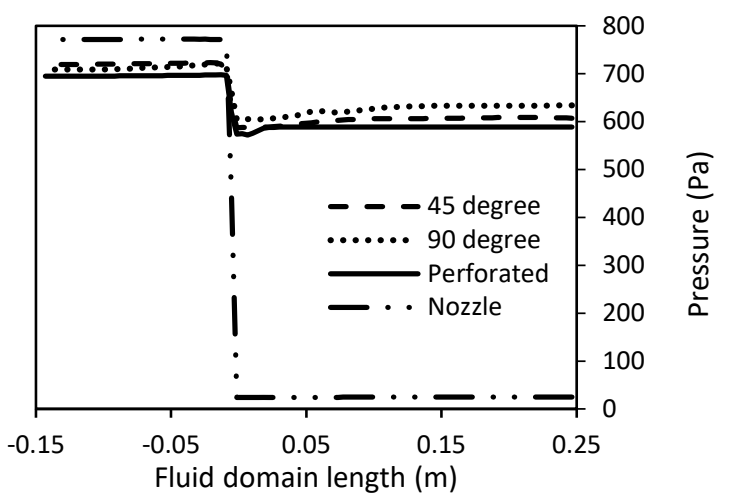

(c)

Figure 5. Simulated pressure over the length of the bed for different distributor designs at velocity corresponding to:

(a) $15 \mathrm{~Hz}$, (b) $30 \mathrm{~Hz}$ and (c) $50 \mathrm{~Hz}$ blower frequency.

The experimental and simulated distributor pressure drops are compared in Table 3 and Figure 6. Both the simulation and experimental results indicated that for all distributor designs, the static pressure increased with increasing blower frequency. The model accuracy was rated according to [28]. For relative error between prediction and experiment that fall less than $10 \%$, the model accuracy was rated as A. While rating $\mathrm{B}$ was given to predictions with relative error less than $20-30 \%$. It can be clearly seen from Table 3 that the maximum percentage error between the experiments and the numerical values is $12 \%$. The plot in Figure 6 shows that the simulated distributor pressure drop values agree well with the experimental data. Hence, the close agreement of the present CFD model with the results of the experiment gives the confidence to use this CFD model for further computations of flow in a bed with different air distributor designs at different air velocities.

Table 3. Comparison of distributor pressure drop and calculated error values between experimental and simulation.

\begin{tabular}{|c|c|c|c|c|c|}
\hline Distributor & $\begin{array}{c}\Delta P_{\exp } \\
(\mathrm{Pa})\end{array}$ & $\begin{array}{c}\Delta P_{c f d} \\
(\mathrm{~Pa})\end{array}$ & $\begin{array}{c}\text { Error } \\
\%\end{array}$ & $\begin{array}{c}\text { Model } \\
\text { accuracy }\end{array}$ & $\begin{array}{l}\text { \%Diff. in exp. } \\
\text { pressure drop }\end{array}$ \\
\hline \multirow{3}{*}{ Perforated Plate } & 9.8 & 10.5 & 7.1 & $\mathrm{~A}$ & - \\
\hline & 39.2 & 42 & 7.1 & A & - \\
\hline & 115.0 & 120 & 4.3 & A & - \\
\hline \multirow{3}{*}{ Multi-nozzles } & 74.2 & 67 & 9.7 & $\mathrm{~A}$ & +656 \\
\hline & 287.0 & 272 & 5.2 & A & +632 \\
\hline & 758.5 & 750 & 1.1 & A & +560 \\
\hline \multirow{3}{*}{$90^{\circ}$} & 9.81 & 9 & 8.3 & $\mathrm{~A}$ & -0.1 \\
\hline & 39.2 & 43 & 9.6 & A & 0 \\
\hline & 107.9 & 100 & 7.3 & $\mathrm{~A}$ & -6.2 \\
\hline \multirow{3}{*}{$45^{\circ}$} & 9.8 & 11 & 12.2 & $\mathrm{~B}$ & 0 \\
\hline & 39.2 & 40 & 2.0 & $\mathrm{~A}$ & 0 \\
\hline & 108.9 & 108 & 0.8 & $\mathrm{~A}$ & -5.3 \\
\hline
\end{tabular}

**A= good, $\mathrm{B}=$ acceptable, $\mathrm{C}=$ marginal, $\mathrm{D}=$ poor

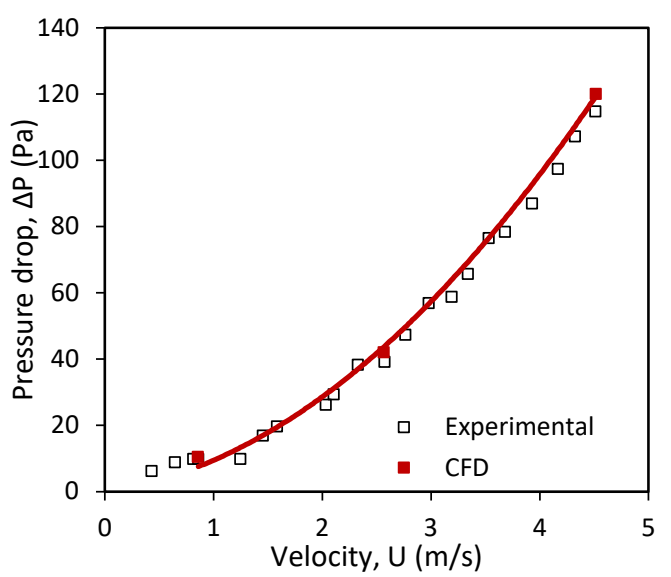

(a)

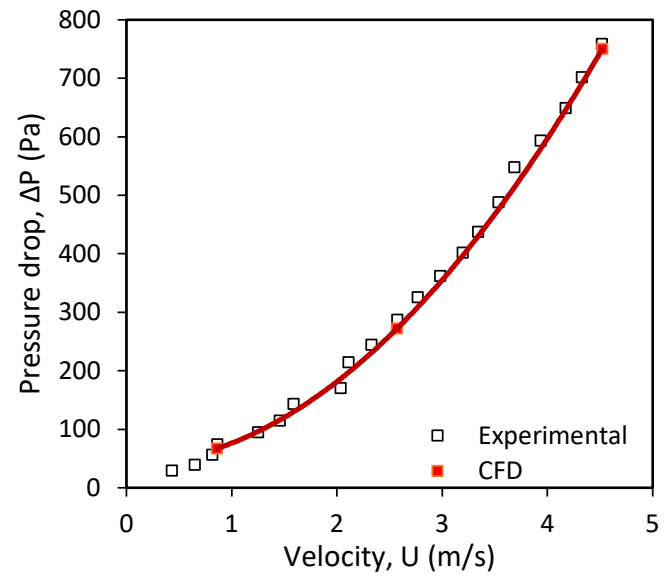

(b) 


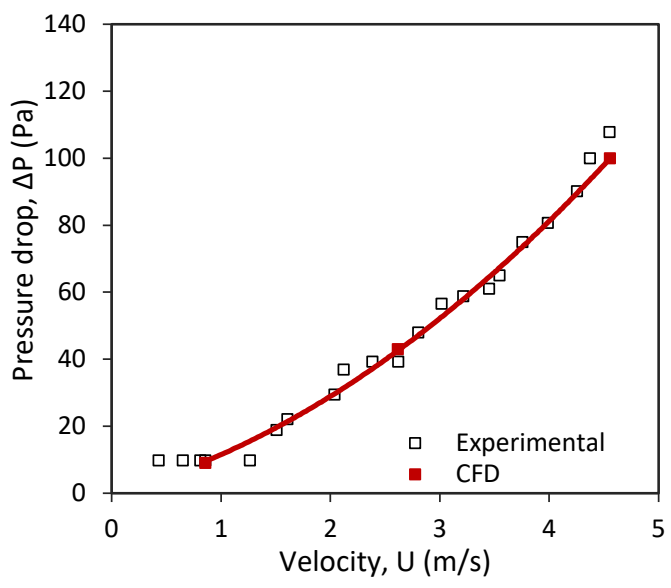

(c)

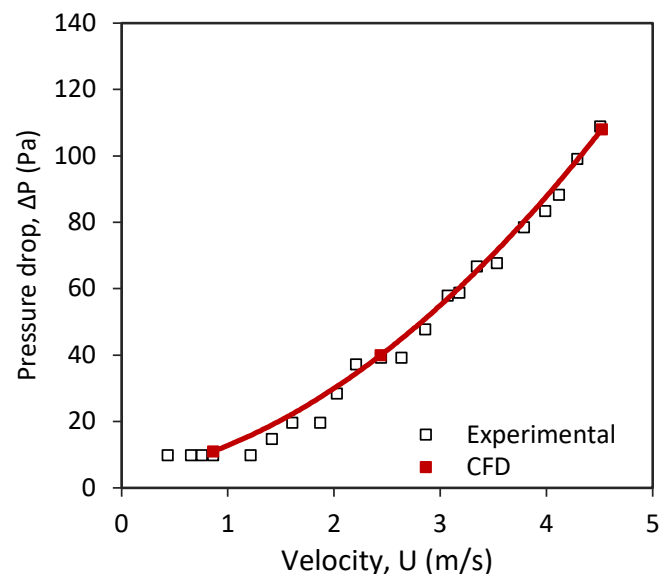

(d)

Figure 6. Comparison of distributor pressure drop between experiment and simulation for (a) perforated, (b) multinozzles, (c) $90^{\circ}$ and (d) $45^{\circ}$ distributors.

\section{Effect of Distributor Designs and Free Area Ratio on Distributor Pressure Drop}

Measurements with an empty bed were carried out to study the effect of distributor configurations such as the variation of distributor free area ratio and air angle of attack on the pressure drop in a fluidised bed. Figure 6 shows the relationship between the air velocity and the distributor pressure drop for the four distributors. It was observed from Fig 6 that the multi-nozzles distributor Figure 6(b) yields higher distributor pressure drop with the averaged maximum value of $749 \mathrm{~Pa}$ between CFD and experimental study. The maximum pressure drop recorded was associated with the higher kinetic head of the inlet air due to the restricted and minimum number of distributor openings and low free area ratio of the multinozzles distributors $\beta=2 \%$. On the other hand, the averaged maximum pressure drop for other distributors was recorded to be about one-fourth of the value of the multi-nozzles pressure drop. The perforated distributor in Figure 6(a) recorded maximum of $118 \mathrm{~Pa}$, followed by $110 \mathrm{~Pa}$ and $113 \mathrm{~Pa}$ for $45^{\circ}$ and $90^{\circ}$ distributors, respectively. The results suggested that low-pressure drop operation in a fluidised bed can be achieved with the increase of free area ratio of the distributor.

However, the results obtained in this study contradicted with the work of Dong et al. [5]. In their study, the authors concluded that fluidisation was more stable in the bed operated in low perforated ratio distributor when operated with an air compressor as the medium of fluidisation. The case, however, is different in this study as the fluidised bed is operated with a lop pressure blower. The low perforated ratio distributor yields higher pressure drop due to inadequate pressure supplied by the blower to provide uniform gas distribution across the distributor holes. It may suggest that the low perforated distributor only work excellently in the fluidised bed system with high operating pressure.

\section{CONCLUSION}

The pressure drop of different types of distributors: perforated plate, multi-nozzles and novel slotted distributors at different air velocity were investigated by using CFD simulations. In the present study, the flow model is based on incompressible isothermal RNG k-epsilon turbulent model. Systematic grid-refinement was conducted to make sure that the simulation results are independent of the computational grid size. The non-dimensional wall distance, $y^{+}$was examined as a key factor to verify the grid independence by comparing results obtained at different grid resolutions. The optimum mesh of the 3D geometries were discretized using 1,776,339, 569,938, 528,789 and 606,714 grid sizes. The pressure drops across the distributors, pressure below the distributor, velocity at the entry to the plenum chamber and outlet of the bed were obtained experimentally and then compared with simulation data. The model accuracy was used to rate the percentage error between the experiments and the numerical data. The maximum percentage error between the experiments and the numerical values was obtained at $12 \%$. The simulated distributor pressure drop values were shown to agree well with the experimental data. Hence, the close agreement of the present CFD model with the results of the experiments gives the confidence to use this CFD model for further computations of flow in a bed with different air distributor designs at different air velocities. The multi-nozzles distributor yields higher distributor pressure drop with an averaged maximum value of $749 \mathrm{~Pa}$ followed by perforated, $45^{\circ}$ and $90^{\circ}$ inclined distributors. The maximum pressure drop recorded was associated with the higher kinetic head of the inlet air due to the restricted and minimum number of distributor openings and low free area ratio. The results suggested that low-pressure drop operation in a fluidised bed can be achieved with the increase of free area ratio of the distributor.

\section{ACKNOWLEDGEMENT}

The authors wish to express their gratitude to the Faculty of Mechanical and Manufacturing Engineering, Universiti Malaysia Pahang (UMP), Pekan, Pahang, Malaysia for providing the research facilities and supporting the research under University Research Grant RDU190383 and Malaysia of Higher Education Research Grant (FRGS/1/2019/TK10/UMP/02/26). 


\section{REFERENCES}

[1] Yang X, Zhao Y, Luo Z, et al. Effects of sintered metal distributor on fluidisation quality of the air dense medium fluidised bed. Mining Science and Technology (China) 2011; 21: 681-685.

[2] Vakhshouri K, Grace JR. Effects of the plenum chamber volume and distributor geometry on fluidised bed hydrodynamics. Particuology 2010; 8: 2-12.

[3] Huilin L, Yunhua Z, Ding J, et al. Numerical Modeling of Gas Tubular Distributors in Bubbling Fluidized-Bed Incinerators. Industrial \& Engineering Chemistry Research 2006; 45: 6818-6827.

[4] Akbari V, Nejad Ghaffar Borhani T, Aramesh R, et al. Evaluation of hydrodynamic behavior of the perforated gas distributor of industrial gas phase polymerisation reactor using CFD-PBM coupled model. Computers \& Chemical Engineering 2015; 82: 344-361.

[5] Dong S, Cao C, Si C, et al. Effect of Perforated Ratios of Distributor on the Fluidization Characteristics in a Gas-Solid Fluidised Bed. Industrial \& Engineering Chemistry Research 2009; 48: 517-527.

[6] Ngo SI, Lim Y-I, Song B-H, et al. Effects of fluidisation velocity on solid stack volume in a bubbling fluidised-bed with nozzle-type distributor. Powder Technology 2015; 275: 188-198.

[7] Sobrino C, Almendros-Ibañez J a., Santana D, et al. Fluidisation of Group B particles with a rotating distributor. Powder Technology 2008; 181: 273-280.

[8] Sobrino C, Acosta-Iborra a., Santana D, et al. Bubble characteristics in a bubbling fluidised bed with a rotating distributor. International Journal of Multiphase Flow 2009; 35: 970-976.

[9] Gómez-Hernández J, Soria-Verdugo A, Briongos JV, et al. Fluidised bed with a rotating distributor operated under defluidization conditions. Chemical Engineering Journal 2012; 195-196: 198-207.

[10] Sobrino C, Ellis N, de Vega M. Distributor effects near the bottom region of turbulent fluidised beds. Powder Technology 2009; 189: 25-33.

[11] Mohideen MF, Sreenivasan B, Sulaiman SA, et al. Heat transfer in a swirling fluidised bed with geldart type-D particles. Korean Journal of Chemical Engineering 2012; 29: 862-867.

[12] Miin CS, Sulaiman SA, Raghavan VR, et al. Hydrodynamics of multi-sized particles in stable regime of a swirling bed. Korean Journal of Chemical Engineering 2015; 32: 2361-2367.

[13] Kaewklum R, Kuprianov VI, Douglas PL. Hydrodynamics of air-sand flow in a conical swirling fluidised bed: A comparative study between tangential and axial air entries. Energy Conversion and Management 2009; 50: 2999-3006.

[14] Sreenivasan B, Raghavan VR. Hydrodynamics of a swirling fluidised bed. Chemical Engineering and Processing: Process Intensification 2002; 41: 99-106.

[15] Yudin ASM, Raghavan VR, Narahari M. A mathematical model for residence time distribution analysis in swirling fluidised bed. In: National Postgraduate Conference (NPC), 2011. 2011, pp. 1-5.

[16] Ahmmad Shukrie. Studies on the residence time distribution of solids in a swirling fluidised bed. Universiti Teknologi Petronas, 2012.

[17] Shukrie A, Anuar S, Alias A. Characterization and Development of Geldart's Fluidising Velocity Profile of Sand Particles for the Application in Fluidized Bed Combustor (FBC). In: Yacob AN, Mohamed M, Megat Hanafiah KMA (eds) Regional Conference on Science, Technology and Social Sciences (RCSTSS 2014): Science and Technology. Singapore: Springer Singapore, 2016, pp. 147-156.

[18] Shukrie A, Anuar S, Alias A. Heat Transfer of Alumina Sands in Fluidized Bed Combustor with Novel Circular Edge Segments Air Distributor. Energy Procedia 2015; 75: 1752-1757.

[19] Castilla R, Gamez-Montero PJ, Ertrk N, et al. Numerical simulation of turbulent flow in the suction chamber of a gearpump using deforming mesh and mesh replacement. International Journal of Mechanical Sciences 2010; 52: 1334-1342.

[20] Sergio G, Marcelo R, Francois G. Assessment study of k- $\varepsilon$ turbulence models and near- wall modeling for steady state swirling flow analysis in draft tube using fluent. Engineering Applications of Computational Fluid Mechanics 2011; 5: 459-478.

[21] Noor MM, Andrew P.Wandel TY. Detail guide for CFD on the simulation of biogas combustion in bluff-body mild burner. In: International Conference on Mechanical Engineering Research (ICMER2013). 2013, p. PID:342.

[22] Noor MM, Andrew P.Wandel TY. Design and development of mild combustion burner. Journal of Mechanical Engineering and Sciences (JMES) 2013; 5: 662-676.

[23] Noor MM, Wandel AP, Yusaf T. The Development of Mild Combustion Open Burner Experimental Setup. International Conference on Mechanical Engineering Research (ICMER2013) 2013; 2030: PID:341.

[24] ANSYS, I. (2013). Fluent Theory Guide. Retrieved, from: http://148.204.81.206/Ansys/150/ANSYS Fluent Theory Guide.pdf, January 1, 2020.

[25] Saxena, A. (2015). Guidelines for Specification of Turbulence at Inlet Boundaries. Retrieved from: http://www.esicfd.com/content/view/877/192/, November 2, 2019.

[26] Richenberg, E. A. (2015). Turbulent Pipe Flow - Numerical Results. Retrieved from: https://confluence.cornell.edu/display/SIMULATION/Turbulent+Pipe+Flow+-+Numerical+Results, November 1, 2019

[27] Liu W, Bai B. A numerical study on helical vortices induced by a short twisted tape in a circular pipe. Case Studies in Thermal Engineering 2015; 5: 134-142.

[28] Zhang Z, Zhang W, Zhai ZJ, et al. Evaluation of various turbulence models in predicting airflow and turbulence in enclosed environments by CFD: Part 2-Comparison with Experimental Data from Literature. HVAC\&R Research 2007; 13: 871886. 